\title{
Healthcare workers and health care-associated infections: knowledge, attitudes, and behavior in emergency departments in Italy
}

\author{
Cristiana Parmeggiani, Rossella Abbate, Paolo Marinelli, Italo F Angelillo*
}

\begin{abstract}
Background: This survey assessed knowledge, attitudes, and compliance regarding standard precautions about health care-associated infections (HAls) and the associated determinants among healthcare workers (HCWs) in emergency departments in Italy.
\end{abstract}

Methods: An anonymous questionnaire, self-administered by all HCWs in eight randomly selected non-academic acute general public hospitals, comprised questions on demographic and occupational characteristics; knowledge about the risks of acquiring and/or transmitting HAls from/to a patient and standard precautions; attitudes toward guidelines and risk perceived of acquiring a HAl; practice of standard precautions; and sources of information.

Results: HCWs who know the risk of acquiring Hepatitis $\mathrm{C}(\mathrm{HCV})$ and Human Immunodeficiency Virus (HIV) from a patient were in practice from less years, worked fewer hours per week, knew that a HCW can transmit HCV and HIV to a patient, knew that HCV and HIV infections can be serious, and have received information from educational courses and scientific journals. Those who know that gloves, mask, protective eyewear, and hands hygiene after removing gloves are control measures were nurses, provided care to fewer patients, knew that HCWs' hands are vehicle for transmission of nosocomial pathogens, did not know that a HCW can transmit HCV and HIV to a patient, and have received information from educational courses and scientific journals. Being a nurse, knowing that HCWs' hands are vehicle for transmission of nosocomial pathogens, obtaining information from educational courses and scientific journals, and needing information were associated with a higher perceived risk of acquiring a HAI. HCWs who often or always used gloves and performed hands hygiene measures after removing gloves were nurses, provided care to fewer patients, and knew that hands hygiene after removing gloves was a control measure.

Conclusions: HCWs have high knowledge, positive attitudes, but low compliance concerning standard precautions. Nurses had higher knowledge, perceived risk, and appropriate HAls' control measures than physicians and HCWs answered correctly and used appropriately control measures if have received information from educational courses and scientific journals.

\section{Background}

Health care-associated infections (HAIs) are a serious problem in the healthcare services as they are common causes of illness and mortality among hospitalized patients. Currently, between $5 \%$ and $10 \%$ of patients admitted to acute care hospitals acquire at least one infection and over the last decades the incidence has

\footnotetext{
* Correspondence: italof.angelillo@unina2.it

* Correspondence: italof.angelillo@unina2.it
Department of Public, Clinical and Preventive Medicine, Second University of Naples, Naples, Italy
}

(c) 2010 Parmeggiani et al; licensee BioMed Central Ltd. This is an Open Access article distributed under the terms of the Creative Commons Attribution License (http://creativecommons.org/licenses/by/2.0), which permits unrestricted use, distribution, and reproduction in any medium, provided the original work is properly cited. increased in both the United States and Europe [1-5]. Several effective evidence-based interventions for reducing the occurrence of HAIs has been proposed, and the Centers for Disease Control and Prevention has developed specific guidelines aimed at preventing the transmission of pathogens within the hospital setting [6]. In Italy, health authorities consider extremely desirable that all healthcare institutions establish and maintain a surveillance system for HAIs $[7,8]$.

Emergency care setting is an area in which the potential risk is most imminent for transmission of HAIs to 
patients or to those healthcare workers (HCWs) who treat them. Indeed, these HCWs are in the forefront of assisting patients prior a diagnosis, who are critically ill, and with life-threatening conditions. To this end, there has been limited attention paid to investigating knowledge, attitudes, and behavior of HCWs' regarding control policies within this setting [9-12]. Therefore, the objectives of this study were to provide an assessment of the level of knowledge, attitudes, and compliance regarding standard precautions about HAIs among HCWs in emergency departments (EDs) in an area of Italy, and to identify the determinants associated with them. It has been hypothesized that participants more knowledgeable perceive a lower risk of acquiring a HAI from the patients and perform their medical duties with better compliance regarding standard precautions and that HCWs who receive information from educational courses and scientific journals are more likely to be more knowledgeable, to perceive a lower risk, and to perform more appropriate behaviors.

\section{Methods}

Between April 2006 and June 2007 a cross-sectional study was conducted at eight randomly selected nonacademic acute general public hospitals in the geographic area of Caserta and Naples (Italy). All 550 HCWs working in the EDs were selected.

The medical director and the ED head of each hospital received a letter with the description of the survey and requesting consent for the HCWs to participate. The medical directors addressed a letter to all HCWs explaining the enrollment and the purpose of the survey, assuring that response was completely voluntary, that information provided would be used solely for fulfilling the research aims, and a self-administered anonymous questionnaire accompanied by an envelope to facilitate its return. Consent to participate was implied by the return of the completed questionnaire.

The questionnaire comprised five categories of questions: (1) demographic and occupational characteristics; (2) knowledge about the risks of acquiring and/or transmitting certain HAIs for/to a patient and standard precautions for prevention; (3) attitudes toward precautionary guidelines and perception of the risk of acquiring HAI; (4) practice of standard precautions; and (5) from which sources they received up-to-date information about HAIs [see Appendix A]. Correct answers to each item were based on a review of the available literature as well as policies and guidelines $[6,13]$.

The content of the questionnaire was validated with interviews and discussions with other experts in the field, and it was modified where necessary. Final questionnaire content, comprehensibility, clarity, and format were developed and validated on input of a volunteer sample of $30 \mathrm{HCWs}$ in a small pilot-test.

The study protocol as well as the questionnaire was approved by Ethical Committee of the Second University of Naples.

\section{Statistical analysis}

Multivariate analysis was carried out using stepwise logistic and linear regression techniques to establish whether the predictor variables were independently associated with the following outcomes of interest: knowledge about the risk for a $\mathrm{HCW}$ of acquiring both Hepatitis C (HCV) and Human Immunodeficiency Virus (HIV) infections from a patient (Model 1); knowledge that using standard precautions (gloves, mask, protective eyewear) and hands hygiene after removing gloves are HAIs control measures (Model 2); perceived risk of acquiring a HAI from a patient (Model 3); using often or always gloves when at direct contact with a patient and hands hygiene measures after removing gloves (Model 4). For purposes of analysis, the outcome variables originally consisting of multiple categories were reduced to two levels. In Model $1, \mathrm{HCW}$ s were classified, according to questions $\mathrm{B} 1 \mathrm{a}$ and $\mathrm{B} 1 \mathrm{c}$, as those who knew the risk for a $\mathrm{HCW}$ of acquiring both $\mathrm{HCV}$ and HIV infections from a patient versus all others; in Model 2, they were grouped, according to questions B4 and B6, as those who knew that using standard precautions (gloves, mask, protective eyewear) and hands hygiene after removing gloves are HAIs control measures versus all others; and in Model 4, HCWs were grouped, according to questions D3 and D5, to whether they often or always used gloves when at direct contact with a patient and hands hygiene measures after removing gloves versus all others. The following independent variables were included in all models: gender (male $=0$, female $=1$ ), age (continuous, in years), working category ( physician $=0$, nurse $=1$ ), number of years in practice (continuous), number of patients seen in a workday (continuous), number of working hours in a week (continuous), knowledge about the risk for a HCW of transmitting $\mathrm{HCV}$ and HIV infections to a patient (no $=0$, yes $=1$ ), knowledge that HCV and HIV infections can be serious (no $=0$, yes $=1$ ), knowledge that HCWs' hands are vehicle for transmission of nosocomial pathogens $($ no $=0$, yes $=1$ ), educational courses and scientific journals as sources of information about HAIs (no $=0$, yes $=1$ ), and need of additional information about HAIs $($ no $=0$, yes $=1)$. The following variables were also included: knowledge that the use of standard precautions is a HAIs control measure (no $=0$, yes $=1$ ) in Model 1; knowledge about the risk for a HCW of acquiring $\mathrm{HCV}$ and HIV infections from a patient (no = 0 , yes $=1$ ), and knowledge that invasive procedures are 
a risk factor for HAIs (no $=0$, yes $=1$ ) in Models 2-4; marital status (single/separated/divorced $/$ widowed $=0$, married $=1$ ), number of other persons in the household $(0=0,1=1,2=2,3=3,4=4,>4=5)$, and knowledge that using standard precautions (gloves, mask, protective eyewear) and hands hygiene after removing gloves are HAIs control measures (no $=0$, yes $=1$ ) in Model 3; knowledge that hands hygiene after removing gloves is a HAIs control measure (no $=0$, yes $=1$ ), positive attitude towards the use of guidelines for HAIs control practices (no $=0$, yes $=1$ ), positive attitude toward hands hygiene measures to reduce the risk among patients (no $=0$, yes $=1$ ), positive attitude toward hands hygiene measures to reduce the risk among HCWs (no $=0$, yes $=1)$, and perceived risk of acquiring a HAI (continuous) in Model 4.

The primary analysis was univariate and the variables significantly associated with the outcomes of interest at $p$-value of 0.25 or less were included in the final models. Then, one stepwise multivariate linear regression model and three multivariate logistic regression models were constructed and the significance level for the variables to entry in the model was set at 0.2 and for removal at 0.4 . In the logistic models the association between predictors and outcomes was measured by odds ratios (ORs) and their 95\% confidence intervals (CIs). All tests were two-tailed and a $p$-value of 0.05 or less was defined as statistically significant. The data were analyzed using the statistical software Stata [14].

\section{Results}

Of the 550 surveys distributed, a total of 307 participants returned the questionnaire with a final response rate of 55.8\%. Two-thirds of the respondents were male, the mean age was 44 years, the mean number of years in practice was 11 , and the mean number of patients seen in a day was 30 .

Answers concerning the knowledge of HCWs are reported in Table 1 . A majority $(87.9 \%)$ were aware that a HCW can acquire HCV and HIV from a patient, but

Table 1 Knowledge about health care-associated infections and control measures

\begin{tabular}{|c|c|c|c|}
\hline Number of question & Questions (correct response) & n & $\%$ \\
\hline \multicolumn{4}{|c|}{ Health care-associated infections that a healthcare worker can acquire from a patient } \\
\hline B1b & Hepatitis C (true) & 289 & 94.1 \\
\hline B1c & Human Immunodeficiency Virus (true) & 277 & 90.2 \\
\hline B1h & Tetanus (false) & 264 & 86 \\
\hline B1d & Influenza (true) & 189 & 61.6 \\
\hline B1a & Hepatitis B (true) & 177 & 57.7 \\
\hline B1i & Tuberculosis (true) & 122 & 39.7 \\
\hline Bif & Mumps (true) & 43 & 14 \\
\hline B1g & Rubella (true) & 43 & 14 \\
\hline B11 & Varicella (true) & 40 & 13 \\
\hline Ble & Measles (true) & 35 & 11.4 \\
\hline \multicolumn{4}{|c|}{ Health care-associated infections that a healthcare worker can transmit to a patient } \\
\hline B2h & Tetanus (false) & 297 & 96.7 \\
\hline B2d & Influenza (true) & 210 & 68.4 \\
\hline B2b & Hepatitis C (true) & 95 & 30.9 \\
\hline B2C & Human Immunodeficiency Virus (true) & 74 & 24.1 \\
\hline B2i & Tuberculosis (true) & 48 & 15.6 \\
\hline B2a & Hepatitis B (true) & 45 & 14.7 \\
\hline B2f & Mumps (true) & 17 & 5.5 \\
\hline B21 & Varicella (true) & 16 & 5.2 \\
\hline B2e & Measles (true) & 14 & 4.6 \\
\hline B2g & Rubella (true) & 14 & 4.6 \\
\hline \multicolumn{4}{|l|}{ Control measures } \\
\hline B6 & Wearing gloves, mask, and protective eyewear (true) & 289 & 94.1 \\
\hline B4 & Hands hygiene measures after removing gloves (true) & 281 & 91.5 \\
\hline B5 & Changing mask before going to another patient (true) & 222 & 72.3 \\
\hline \multicolumn{4}{|l|}{ Risk factors } \\
\hline B7 & Invasive procedures (true) & 281 & 91.5 \\
\hline B8 & HCWs' hands are vehicle for transmission of nosocomial pathogens (true) & 275 & 89.6 \\
\hline
\end{tabular}

$\mathrm{HCW}=$ Healthcare worker 
less than one-third knew that a HCW can transmit these infections to a patient. Table 2 shows the results of the multivariate analysis regarding the association between the different outcomes of interest and the various explanatory variables. $\mathrm{HCW}$ s with fewer number of years of practice $(\mathrm{OR}=0.9 ; 95 \%$ CI $0.85-0.96)$, who worked fewer hours in a week $(\mathrm{OR}=0.9$; $95 \%$ CI 0.84 0.97), who knew the risk for a $\mathrm{HCW}$ of transmitting $\mathrm{HCV}$ and HIV infections to a patient (OR $=6.07 ; 95 \%$ CI 1.31-28.14), who knew that HCV and HIV infections can be serious $(\mathrm{OR}=8.09 ; 95 \%$ CI $3.31-19.81)$, who have received information about HAIs from educational courses and scientific journals $(\mathrm{OR}=3.54$; $95 \%$ CI 1.22 10.24), and who did not need additional information about HAIs $(\mathrm{OR}=0.06$; $95 \%$ CI $0.01-0.55)$ were more likely to know the risk for a $\mathrm{HCW}$ of acquiring both $\mathrm{HCV}$ and HIV from a patient (Model 1). The vast majority correctly identified as proper HAIs control measures the use of gloves, mask, and protective eyewear $(94.1 \%)$ and hands hygiene measures after removing gloves (91.5\%). Overall, $86.3 \%$ were aware of both preventive measures and this knowledge was significantly higher in nurses (OR $=2.34 ; 95 \%$ CI 1.09-5.01), in HCWs who provided care to fewer patients in a day $(\mathrm{OR}=0.98 ; 95 \%$ CI 0.95-0.99), who knew that HCWs' hands are vehicle for transmission of nosocomial pathogens $(\mathrm{OR}=4.64 ; 95 \%$ CI 1.85-11.68), who received information about HAIs from educational courses and scientific journals $(\mathrm{OR}=3.54 ; 95 \% \mathrm{CI} 1.47-8.5)$, and who did not know the risk for a HCW of transmitting $\mathrm{HCV}$ and HIV infections to a patient (OR $=0.24 ; 95 \%$ CI 0.11-0.5) (Model 2).

Concerning the perceived risk of acquiring a HAI, HCWs' thought to be at high risk with a mean value of 7.3. The multivariate linear regression analysis showed that being a nurse, knowing that HCWs' hands are vehicle for transmission of nosocomial pathogens, obtaining information about HAIs from educational courses and scientific journals, and needing additional information about HAIs were significantly independently associated with a higher level of perceived risk (Model 3). Moreover, HCWs had an extremely positive attitudes since 94.5\% and $89.2 \%$ agreed that guidelines for preventing HAIs should strictly be followed and that hands hygiene measures after treating patients reduces the risk, respectively.

Answers concerning the HCWs who often or always adopt practices to reduce the risk of HAIs are reported in Table 3. Only $57.3 \%$ always wore gloves and $85.2 \%$ of them reported always changing gloves after each patient, while $52.3 \%$ and $79 \%$ always performed hands hygiene measures before and after wearing gloves, respectively. A total of $80.8 \%$ of respondents often or always used gloves and performed hands hygiene measures after removing gloves. This behavior was more frequent in nurses $(\mathrm{OR}=2.33$; 95\% CI 1.13-4.79), in HCWs who provided care to fewer patients $(\mathrm{OR}=0.97 ; 95 \% \mathrm{CI}$ 0.95-0.99), and who knew that hands hygiene after removing gloves was a control measure $(\mathrm{OR}=8.09$; $95 \%$ CI 2.83-23.1) (Model 4).

The most commonly reported source of information about HAIs was educational courses $(71 \%)$ followed by scientific journals (48.2\%); $85.3 \%$, however, claimed to need to update what they already knew.

\section{Discussion}

In this present investigation, a questionnaire was utilized to collect information from a sample of HCWs in randomly selected emergency care setting of Italian hospitals regarding their knowledge, attitudes, and behaviors about HAIs.

Participants' knowledge concerning the various aspects of HAIs was generally high and consistent with current scientific evidence, since the vast majority were aware about some infections that a HCW can acquire from a patient and the standard precautions. In contrast, there are wide areas where the knowledge was lower, particularly regarding infections that a HCW can transmit to a patient. Based on this consideration, this specific population needs to learn more in order to reduce the rate of HAIs. Continuing medical benefits in the hospital environment require continuing educational input.

In this investigation, the working activity was found to be a significant determinant of the amount of knowledge about standard precautions and hands hygiene after removing gloves as control measures for HAIs, their perceived risk of acquiring a HAI, using gloves and performing hands hygiene measures. Nurses were more likely to have a higher level of knowledge, to have a higher perceived risk, and to use appropriate HAIs' control measures than physicians. It is possible that such differences may be attributed to the more active involvement in preventive activities regarding HAIs. Moreover, provision of information about HAIs influence knowledge and behaviors because $\mathrm{HCW}$ s were able to answer correctly and to appropriately use HAIs control measures if they have received information from educational courses and scientific journals. This shows that providing HCWs with appropriate information is enough to ensure understanding, especially in a particular risk group like the sample of this study.

Results from this nationwide survey indicate that most respondents often or always used gloves and performed hands hygiene measures after removing gloves for the prevention of the HAIs. No differences were observed in reported compliance with recommendations according to gender and age of the HCWs. Instead, two independent predictors of compliance were positively associated: 
Table 2 Multivariate logistic $(1,2,4)$ and linear $(3)$ regression models results

\begin{tabular}{|c|c|c|c|}
\hline Variable & OR & $95 \% \mathrm{Cl}$ & $p$ \\
\hline \multicolumn{4}{|l|}{ Model 1. HCWs who know the risk of acquiring HCV and HIV infections from a patient } \\
\hline \multicolumn{4}{|l|}{ Log likelihood $=-81.13, \chi^{2}=63.68(8 \mathrm{df}), p<0.0001$} \\
\hline Know that HCV and HIV infections can be serious & 8.09 & $3.31-19.81$ & $<0.001$ \\
\hline Fewer number of years in practice & 0.9 & $0.85-0.96$ & 0.002 \\
\hline Fewer number of working hours in a week & 0.9 & $0.84-0.97$ & 0.006 \\
\hline Need of additional information about HAls & 0.06 & $0.01-0.55$ & 0.012 \\
\hline Educational courses and scientific journals as sources of information about HAls & 3.54 & $1.22-10.24$ & 0.02 \\
\hline Know the risk for a HCW of transmitting HCV and HIV infections to a patient & 6.07 & $1.31-28.14$ & 0.021 \\
\hline Older age & 1.06 & $0.99-1.14$ & 0.08 \\
\hline Fewer number of patients seen in a day & 0.99 & $0.96-1.01$ & 0.32 \\
\hline
\end{tabular}

Model 2. HCWs who know that using standard precautions and hands hygiene after removing gloves are HAl's control measures

Log likelihood $=-98.84, \chi^{2}=47.37(6 \mathrm{df}), p<0.0001$

Not know the risk for a HCW of transmitting HCV and HIV infections to a patient

Know that HCWs hands are vehicle for transmission of nosocomial pathogens

Educational courses and scientific journals as sources of information about HAls

Working as a nurse

Fewer number of patients seen in a workday

$\begin{array}{lcc}0.24 & 0.11-0.5 & <0.001 \\ 4.64 & 1.85-11.68 & 0.001 \\ 3.54 & 1.47-8.5 & 0.005 \\ 2.34 & 1.09-5.01 & 0.029 \\ 0.98 & 0.95-0.99 & 0.05 \\ 0.97 & 0.93-1.01 & 0.16\end{array}$

Fewer number of years in practice

0.97

0.93-1.01

0.16

Model 4. HCWs who often or always use gloves when at direct contact with a patient and performed hands hygiene measures after removing gloves

Log likelihood $=-114.73, \chi^{2}=71.02(10 \mathrm{df}), p<0.0001$

Know that hands hygiene after removing gloves is a HAls control measure

Fewer number of patients seen in a workday

Working as a nurse

Know that invasive procedures are a risk factor for $\mathrm{HAl}$

Educational courses and scientific journals as sources of information about HAls

Know the risk for a HCW of acquiring HCV and HIV infections from a patient

Higher perceived risk for a HCW of acquiring a HAI

Beliefs that the use of guidelines for HAls control practices do not reduce the risk

Not know the risk for a HCW of transmitting HCV and HIV infections to a patient

Younger age

Variable

Model 3. HCWs who perceive a risk of acquiring a HAl from a patient

$\mathrm{F}(10,296)=4.88, p<0.0001, R^{2}=14.2 \%$, adjusted $R^{2}=11.3 \%$

Need of additional information about HAls

Working as a nurse

Educational courses and scientific journals as sources of information about HAls

Know that HCWs hands are vehicle for transmission of nosocomial pathogens

Know the risk for a HCW of transmitting HCV and HIV infections to a patient

Fewer number of years in practice

Know that HCV and HIV infections can be serious

Know the risk for a HCW of acquiring HCV and HIV infections from a patient

Higher number of other persons in the household

Higher number of patients seen in a workday

Constant
8.09

0.97

\begin{tabular}{cc}
$2.83-23.1$ & $<0.001$ \\
$0.95-0.99$ & 0.014 \\
$1.13-4.79$ & 0.022 \\
$0.92-7.84$ & 0.07 \\
$0.89-5.2$ & 0.09 \\
$0.88-5.58$ & 0.09 \\
$0.96-1.37$ & 0.12 \\
$0.1-1.61$ & 0.2 \\
$0.27-1.4$ & 0.25 \\
$0.94-1.02$ & 0.31 \\
\hline $\mathrm{t}$ & $p$
\end{tabular}

Coeff.

2.69

2.15

2.22

1.15

0.4

0.62

0.98

$\mathrm{t}$

$<00$

$\begin{array}{lll}1.23 & 3.86 & <0.001\end{array}$

$\begin{array}{lll}0.66 & 3.01 & 0.003\end{array}$

$\begin{array}{lll}0.76 & 2.43 & 0.016\end{array}$

$\begin{array}{lll}0.72 & 1.98 & 0.049\end{array}$

$\begin{array}{lll}0.32 & 1.24 & 0.22\end{array}$

$-0.02$

$-1.2$

0.23

0.37

1.19

0.23

0.38

1.06

0.29

0.07

0.01

1.03

0.3

0.33

3.6

$\mathrm{HCW}=$ Healthcare worker; HCV = Hepatitis C Virus; HIV = Human Immunodeficiency Virus; HAI = Health care-associated infection 
Table 3 Healthcare workers who often or always adopt practice to reduce the risk of health care-associated infections

\begin{tabular}{clcc}
\hline Number of question & Practice & $\mathbf{n}$ & \% \\
\hline D10 & Placing needles in sharp's containers & 278 & 90.5 \\
D3 & Wearing gloves when at direct contact with a patient & 272 & 88.6 \\
D6 & Changing gloves before going to another patient & 267 & 266 \\
D2 & Hands hygiene measures before going to another patient & 264 & 86.6 \\
D5 & Hands hygiene measures after removing gloves & 240 & 86 \\
D1 & Hands hygiene measures before starting the working activity & 202 & 78.2 \\
D4 & Hands hygiene measures before wearing gloves & 151 & 45.8 \\
D9 & Recapping needles after using & 110 & 39.2 \\
D7 & Wearing protective eyewear when at direct contact with a patient & 109 & 35.8 \\
D8 & Wearing mask when at direct contact with a patient & 35.5 \\
\hline
\end{tabular}

fewer patients cared in a day and know that hands hygiene measures after removing gloves is a control measure. The finding that lower knowledge is linked to the underuse of appropriate control measures confirm the need to intensify educational programs. Moreover, the use of protective barriers was considerably lower than those observed in previous surveys. For instance, in a sample of emergency medicine residents in the United States, $96 \%$ and $99 \%$ used gloves at least $95 \%$ of the time for irrigation and incision and for drainage procedures, respectively [11]. Physicians and nurses in pediatric EDs in Canada self-reported a high rate of handwashing before and after all patients with a mean score, out of 5 possible points, of 4.9 and 4.5, respectively, and for wearing gloves when examining patients of 3.3 and 3.2 [10]. A national telephone survey among orthopedic surgeons in accident and EDs throughout England found that $99 \%$ routinely used gloves in a major trauma scenario, but only $18 \%$ and $21 \%$ used face mask and eye protection, respectively [12]. Finally, our values were higher than those in EDs in the United Kingdom and New Zealand, with values of $27 \%$ and $58 \%$ and of $14 \%$ and $12 \%$, respectively, for asepsis in invasive procedures and hands hygiene between patient consultations [9].

Another key finding was that the attitudes towards HAIs are encouraging, since a high percentage of respondents reported positive global and specific beliefs. In particular, $94.5 \%$ indicated that guidelines should be established and followed. The multivariate analysis indicated that being nurses, knowing that HCWs' hands are vehicle for transmission of nosocomial pathogens, requiring and receiving information about HAIs were significantly independent predictors of a high perceived risk of acquiring a HAI.

There are some potential limitations in the design and measurements of this study that should be considered when interpreting the results. First, it provides as a cross-sectional study, only circumstantial evidence for the casual nature of the relationships that have been observed. No direct relationship between variables and outcomes can be proved but substantial evidence has been demonstrated for the association discussed. A second limitation is the potential reporting bias associated with the self-administered questionnaire. Concern always exists about accuracy in these surveys and it is difficult to determine with certainty whether the responses reflect what HCWs actually do. Specifically, compliance to control measures was based solely upon the subjective views of HCWs with the possibility that they tend to over-report compliance, notwithstanding that all interviews were anonymous. A more effective method of measuring compliance would be the direct observation of actual practice although the effect of being monitored may improve compliance by itself. A final limitation was that the response rate of $55 \%$ was disappointingly low, and one reason may be the time constraints faced by busy practitioners. We were not able to gather detailed information on non-respondents and, therefore, we were unable to assess whether there was a subgroup that systematically failed to respond. Although this response rate does not reflect internal validity of the findings, it may decrease the overall generalizability of the results to all HCWs in EDs. However, because HCWs tend to be relatively homogeneous with respect to attitudes and behaviors, the response rate may not have led to significant non-response bias.

\section{Conclusions}

HCWs in EDs show high levels of knowledge and positive attitudes, but the low compliance rate with regard to standard precautions about HAIs clearly reveal the urgency to implement initiatives for improving healthcare policies and to stress the need for adopting and following preventive recommendations by all HCWs.

\section{APPENDIX A}

Tables 4, 5, 6, 7 and 8 . 


\section{Table 4 Demographic and occupational characteristics section of the questionnaire}

A. DEMOGRAPHIC AND OCCUPATIONAL CHARACTERISTICS

This section is designed to gather information about your socio-demographic and occupational characteristics.

A1. What is your gender? $\square$ Male $\square$ Female

A2. How old were you on your last birthday? years

A3. What is your marital status? $\square$ Married $\square$ Single (never married) $\square$ Other (specify

A4. How many persons are there in your household? (not counting you)

A5. What is your working category in the Emergency Department (ED)?

A6. How many years have you been working in an ED?

A7. How many patients do you provide care in a day in the ED?

A8. How many hours per week do you work in the ED?

Table 5 Knowledges section of the questionnaire

\section{B. KNOWLEDGES}

This section is designed to explore your knowledge related to health care-associated infections (HAls)

B1. Which of the following infections a healthcare worker $(\mathrm{HCW})$ can acquire from a patient? (check one or more)
a. $\square$ Hepatitis $B$
b. $\cdot$ Hepatitis $C$
c. $\square$ Human Immunodeficiency Virus
d. $\square$ Influenza
e. Measles
f. $\square$ Mumps
g. $\square$ Rubella
h. $\square$ Tetanus

i. Tuberculosis

I. Varicella

B2. Which of the following infections a HCW can transmit to a patient? (check one or more)
a. $\square$ Hepatitis $B$
b. $\cdot$ Hepatitis $C$
c. $\mathrm{Human}$ Immunodeficiency Virus
d. Influenza
e. $\square$ Measles
f. $\square$ Mumps
g. $\square$ Rubella
h. $\square$ Tetanus
i. $\square$ Tuberculosis
I. $\square$ Varicella

B3. Which of the following infections can be serious? (check one or more)
a. $\square$ Hepatitis B
b. Hepatitis C
c. $\square$ Human Immunodeficiency Virus
d. Influenza
e. Measles
f. $\square$ Mumps
g. $\mathrm{Rubella}$
h. $\square$ Tetanus
i. Tuberculosis
I. Varicella

For each statement regarding HAls, please check whether you agree, are uncertain or disagree

$\begin{array}{lll}\text { B4. Hands hygiene after removing } & \text { Agree } & \text { Uncertain } \\ \text { gloves is a HAls control measure } & \square \\ \text { B5. Changing mask before going to } & \square \\ \text { another patient is a HAls control measure } & \square \\ \text { B6. Wearing gloves, mask, and protective } & \\ \text { eyewear are a HAls control measures } & \square \\ \text { B7. Invasive procedures are a risk factor for HAls } & \square \\ \text { B8. HCWs' hands are a vehicle for transmission } & \square\end{array}$

\section{Table 6 Attitudes section of the questionnaire}

\section{ATTITUDES}

This section is designed to explore your attitudes towards HAls. For each statement check whether you agree, are uncertain or disagree.

C1. The use of guidelines for HAls control practices reduce the risk

C2. Hands hygiene measures reduce the risk of HAls among patients

C3. Hands hygiene measures reduce the risk of HAls among HCWs

C4. How do you perceive your risk of acquiring a HAI on a 1 to 10 scale with 1 meaning no risk and 10 very much risk?
No risk
$\begin{array}{llllll}5 & 6 & 7 & 8 & 9 & 10\end{array}$
Very much risk

$\begin{array}{ccc}\text { Agree } & \text { Uncertain } & \text { Disagree } \\ \square & \square & \square \\ \square & \square & \square \\ \square & \square & \square\end{array}$




\section{Table 7 Behaviors section of the questionnaire}

\section{BEHAVIORS}

This section is designed to gather information about your behaviors. Check how often do you adopt each of the following practices to reduce the risk of HAls.

D1. Hands hygiene measures before starting the working activity

D2. Hands hygiene measures before going to another patient

D3. Wearing gloves when at direct contact with a patient

D4. Hands hygiene measures before wearing gloves

D5. Hands hygiene measures after removing gloves

D6. Changing gloves before going to another patient

D7. Wearing protective eyewear when at direct contact with a patient

D8. Wearing mask when at direct contact with a patient

D9. Recapping needles after using

D10. Placing needles in sharp's containers

D11. Using syringes with retractable needle

D12. Using syringes with protective shield

D13. Using scalpels with protective shield

D14. Using intravenous cannulation with retractable needle

$\begin{array}{lllll}\text { Always } & \text { Often } & \text { Sometimes } & \text { Rarely } & \text { Never } \\ \square & \square & \square & \square & \square \\ \square & \square & \square & \square & \square \\ \square & \square & \square & \square & \square \\ \square & \square & \square & \square & \square \\ \square & \square & \square & \square & \square \\ \square & \square & \square & \square & \square \\ \square & \square & \square & \square & \square \\ \square & \square & \square & \square & \square \\ \square & \square & \square & \square & \square \\ \square & \square & \square & \square & \square \\ \square & \square & \square & \square & \square \\ \square & \square & \square & \square & \square \\ \square & \square & \square & \square & \square \\ \square & \square & \square & \square & \square\end{array}$

Table 8 Source of information section of the questionnaire

\section{E. INFORMATION}

This section is designed to ask questions about your sources of information.

E1. From which of the following sources do you receive information about HAls? (check one or more)
$\square$ None
$\square$ Scientific journals
$\square$ Mass-media
$\square$ Educational courses
$\square$ Physicians
$\square$ Other (please specify
$\square$ Yes
$\square \mathrm{No}$

\section{Acknowledgements}

Preliminary results have been presented at the $43^{\circ}$ National Congress of the Italian Public Health Association, October 1-4, 2008, Bari, Italy.

We would like to thank the participants for time and effort in responding to this questionnaire.

\section{Authors' contributions}

CP participated in the design of the study, statistical analysis, interpretation of the data, and collected the data. RA participated in the statistical analysis and interpretation of the data. PM participated in the design of the study and interpretation of the data. IFA, the principal investigator, designed the study, was responsible for the data collection, statistical analysis and interpretation of the data, and wrote the article. All Authors read and approved the final manuscript.

\section{Competing interests}

The authors declare that they have no competing interests.

Received: 25 August 2009 Accepted: 23 February 2010 Published: 23 February 2010

\section{References}

1. Eriksen HM, Iversen BG, Aavitsland P: Prevalence of nosocomial infections in hospitals in Norway, 2002 and 2003. J Hosp Infect 2005, 60:40-45.

2. Pittet $D$, Allegranzi $B$, Sax H, Bertinato L, Concia E, Cookson B, et al: Considerations for a WHO European strategy on health-care-associated infection, surveillance, and control. Lancet Infect Dis 2005, 5:242-250.

3. Hopmans TE, Blok HE, Troelstra A, Bonten MJ: Prevalence of hospitalacquired infections during successive surveillance surveys conducted at a university hospital in the Netherlands. Infect Control Hosp Epidemiol 2007, 28:459-465.
4. Klevens RM, Edwards JR, Richards CL Jr, Horan TC, Gaynes RP, Pollock DA, et al: Estimating health care-associated infections and deaths in U.S. hospitals, 2002. Public Health Rep 2007, 122:160-166.

5. Pittet D, Allegranzi B, Storr J, Bagheri Nejad S, Dziekan G, Leotsakos A, et al: Infection control as a major World Health Organization priority for developing countries. J Hosp Infect 2008, 68:285-292.

6. Siegel JD, Rhinehart E, Jackson M, Chiarello L, the Health Care Infection Control Practices Advisory Committee: Guideline for isolation precautions: preventing transmission of infectious agents in healthcare settings. [http://www.cdc.gov/ncidod/dhqp/pdf/guidelines/Isolation2007.pdf], Accessed June 30, 2007.

7. Ministero della Sanità: Circolare n.52/1985. Lotta contro le infezioni ospedaliere [http://www.ccm-network.it/documenti_Ccm/prg_area1/Inf_Oss/ Normativa_naz/Circolare52_1985.pdf].

8. Ministero della Sanità: Circolare n.8/1988. Lotta contro le infezioni ospedaliere: la sorveglianza [http://www.ccm-network.t/documenti_Ccm/ prg_area1/Inf_Oss/Normativa_naz/Circolare8_1988.pdf].

9. Al-Damouk M, Pudney E, Bleetman A: Hand hygiene and aseptic technique in the emergency department. J Hosp Infect 2004, 56:137-141.

10. Parker MJ, Goldman RD: Paediatric emergency department staff perceptions of infection control measures against severe acute respiratory syndrome. Emerg Med J 2006, 23:349-353.

11. Ellison AM, Kotelchuck M, Bauchner H: Standard precautions in the pediatric emergency department: knowledge, attitudes, and behaviors of pediatric and emergency medicine residents. Pediatr Emerg Care 2007, 23:877-880.

12. Sundaram $\mathrm{RO}$, Parkinson RW: Universal precaution compliance by orthopaedic trauma team members in a major trauma resuscitation scenario. Ann R Coll Surg Engl 2007, 89:262-267.

13. Bolyard EA, Tablan OC, Williams WW, Pearson ML, Shapiro CN, Deitchman SD, the Hospital Infection Control Practices Advisory Committee: Guideline for infection control in health care personnel, 1998. 
[http://www.cdc.gov/ncidod/dhqp/pdf/guidelines/InfectControl98.pdf], Accessed March 1, 2006

14. Stata Corporation: Stata Reference Manual Release 10. College Station, TX, USA 2007.

\section{Pre-publication history}

The pre-publication history for this paper can be accessed here: http://www. biomedcentral.com/1471-2334/10/35/prepub

doi:10.1186/1471-2334-10-35

Cite this article as: Parmeggiani et al:: Healthcare workers and health

care-associated infections: knowledge, attitudes, and behavior in

emergency departments in Italy. BMC Infectious Diseases 2010 10:35.

Submit your next manuscript to BioMed Central and take full advantage of:

- Convenient online submission

- Thorough peer review

- No space constraints or color figure charges

- Immediate publication on acceptance

- Inclusion in PubMed, CAS, Scopus and Google Scholar

- Research which is freely available for redistribution

Submit your manuscript at www.biomedcentral.com/submit 